OPEN ACCESS

Edited by:

Laszlo Csiba

University of Debrecen, Hungary

Reviewed by:

Christos Krogias

Ruhr University Bochum, Germany

Dimitre Staykov

Independent Researcher, Vienna

Austria

Anna Czlonkowska,

Instytut Psychiatrii i Neurologii w

Warszawie (IPiN), Poland

Danilo Toni,

Sapienza University of Rome, Italy

*Correspondence:

Quanwei He

hequanwei2016@hust.edu.cn

$\mathrm{Bo} \mathrm{Hu}$

hubo@mail.hust.edu.cn

†These authors have contributed equally to this work

Specialty section:

This article was submitted to

Stroke,

a section of the journa

Frontiers in Neurology

Received: 24 February 2020 Accepted: 09 June 2020 Published: 17 July 2020

Citation:

Li Z, You M, Long C, Bi R, Xu H, He Q and Hu B (2020) Hematoma

Expansion in Intracerebral

Hemorrhage: An Update on Prediction and Treatment. Front. Neurol. 11:702. doi: 10.3389/fneur.2020.00702

\section{Hematoma Expansion in} Intracerebral Hemorrhage: An Update on Prediction and Treatment

\author{
Zhifang Li ${ }^{\dagger}$, Mingfeng You ${ }^{\dagger}$, Chunnan Long, Rentang Bi, Haoqiang Xu, Quanwei He* and \\ $\mathrm{Bo} \mathrm{Hu}^{*}$
}

Department of Neurology, Union Hospital, Tongji Medical College, Huazhong University of Science and Technology, Wuhan, China

Intracerebral hemorrhage $(\mathrm{ICH})$ is the most lethal type of stroke, but there is no specific treatment. After years of effort, neurologists have found that hematoma expansion $(\mathrm{HE})$ is a vital predictor of poor prognosis in $\mathrm{ICH}$ patients, with a not uncommon incidence ranging widely from 13 to $38 \%$. Herein, the progress of studies on HE after $\mathrm{ICH}$ in recent years is updated, and the topics of definition, prevalence, risk factors, prediction score models, mechanisms, treatment, and prospects of HE are covered in this review. The risk factors and prediction score models, including clinical, imaging, and laboratory characteristics, are elaborated in detail, but limited by sensitivity, specificity, and inconvenience to clinical practice. The management of HE is also discussed from bench work to bed practice. However, the upmost problem at present is that there is no treatment for HE proven to definitely improve clinical outcomes. Further studies are needed to identify more accurate predictors and effective treatment to reduce HE.

Keywords: hematoma expansion, intracerebral hemorrhage, risk factor, prediction score model, treatment

\section{INTRODUCTION}

Intracerebral hemorrhage (ICH) accounts for about $10-20 \%$ of all types of stroke $(1,2)$ and almost $40 \%$ of patients who suffer from ICH will die within the first month, while only $12-39 \%$ of survivors achieve long-term functional independence (2), which makes it a severe public health problem. Unfortunately, after decades of effort there is no specific treatment yet for ICH, but recently HE has been found to be a modifiable and independent predictor of clinical neurological deterioration in intracerebral hemorrhagic patients. HE prevention has been accepted as one of the most promising therapeutic strategies in ICH treatment (3). Although numerous efforts have been made to select ICH patients at high risk of developing HE, no uniform prediction score model can be concluded from current studies, which therefore impedes the early detection and subsequent active intervention by clinicians. Moreover, once HE occurs in ICH patients, the treatment is extremely limited and the functional prognosis of those patients is unsatisfactory. Thus, it remains a priority to prospectively detect high-risk HE patients as well as administer more active prevention treatment.

This review refers to the definition, prevalence, risk factors/predictors, prediction score models, mechanisms, and treatment progress of HE. In detail, the predictors of HE are summarized to update the view on the prediction, and suggestions are also provided to establish an accurate and easy-to-use prediction score model. Furthermore, we discuss current HE treatment strategies from the viewpoint of clinicians and also point out future directions for the discovery of more effective therapies. 


\section{DEFINITION}

HE is defined based on visually discernible hematoma volume changes between the baseline and follow-up CT, and the evaluation of hematoma volume growth is diverse across HE related studies. As one of the earliest researchers of HE, Fujii et al. defined it as absolute hematoma volume growth of more than $20 \mathrm{ml}$ or relative hematoma volume growth of more than $50 \%$ (4). Later, Brott et al. used relative hematoma volume growth of more than $33 \%$ which can be discovered by CT to define HE (5). Using ROC curve analysis, Kazui et al. applied cut point of hematoma volume increase of $12.5 \mathrm{ml}$ or $40 \%$ (6). Some recently published large clinical trials also used relative hematoma growth of more than 33\% (7), or combined hematoma growth of $6 \mathrm{~mL}$ absolute increase and $33 \%$ relative increase $(8,9)$ to define it. Based on CT angiography contrast extravasation, a $6 \mathrm{~mL}$ absolute increase of hematoma volume was proposed in the studies of Thompson et al. and Delgado et al. $(10,11)$. Of all the different definitions, Dowlatshahi et al. found that absolute growth definitions were more preferable to predict the outcome of ICH (12). Considering that intraventricular hemorrhage (IVH) is a predictor of poor prognosis in ICH, the presence of IVH may also be an indicator of HE. Specifically, Vignan et al. found that addition of IVH into the HE definition improves the prediction of 90 days outcome in ICH patients (13).

A uniform definition of $\mathrm{HE}$ considering convenience of measurement and effectiveness in predicting outcome is needed for further study.

\section{PREVALENCE}

Hemostasis was once thought to be over within min after ICH occurrence, but recently $\mathrm{HE}$ has been found to be a common phenomenon of ICH with advanced radiology (5). The reported incidence of $\mathrm{HE}$ within $6 \mathrm{~h}$ from ICH symptom onset ranges widely from 13 to $38 \%(5,6,12)$, which may be largely explained by different definitions of $\mathrm{HE}$ and different time interval between hematoma measurement in the different studies. In the Intensive Blood Pressure Reduction in Acute Cerebral Hemorrhage Trial 2 (INTERACT2), the incidence of HE was $33.1 \%$ in the control group (14), while it was $25.3 \%$ in Antihypertensive Treatment of Acute Cerebral Hemorrhage 2 (ATACH2) (15). Notably, the incidence of $\mathrm{HE}$ is highest at the hyperacute stage (within $6 \mathrm{~h}$ after symptom onset) and HE usually occurs at the internal capsule, thalamus, and brainstem. Thus, it is necessary to maintain hematoma surveillance, especially at the hyperacute stage of ICH.

\section{RISK FACTORS/PREDICTORS}

ICH patients with high risk factors of developing $\mathrm{HE}$ are predisposed to experience clinical deterioration and closer neurological monitoring is required, while the absence of the predictors may identify ICH patients with low risk of developing HE. Thus, HE predictors have a vital role to play in selecting high-risk ICH patients and subsequently facilitating the individualized treatment. Based on clinical, imaging, and laboratory characteristics, a series of risk factors/predictors of HE have been identified.

\section{CLINICAL PREDICTORS}

Systolic blood pressure (SBP) is positively related to the initial hematoma volume in ICH patients (16) and the risk of $\mathrm{HE}$ is much higher in patients with post-admission SBP over 160 mmHg $(P=0.0074)(17,18)$, which may be partly explained by the continuous rupturing and hemorrhaging of small vessels, thus making early blood pressure a potential treatment target. Although baseline blood pressure variability (BPV) is not associated with HE (19), post-admission BPV independently predicts HE as well as poor functional outcomes (20). High mean arterial pressure (MAP) is positively related to HE as well (19).

Medication with antiplatelet or anticoagulant drugs also increases the risk of HE. In high-income countries, more than a quarter of patients with $\mathrm{ICH}$ are on prior antiplatelet therapy (APT) (21). An observational study by Toyoda et al. showed that APT was an independent predictor of HE (22), while in the Cerebral Hemorrhage and NXY-059 treatment trial, antiplatelet drug use at ICH onset was not associated with $\mathrm{HE}$ (23). On account of their methodological difference, recently this controversy has been laid to rest by a meta-analysis which supports prior APT as a predictor of HE (24). For those with prior medication with anticoagulants, prior oral anticoagulation (OAC) use is not only an independent predictor of larger initial hematoma volume (25) but also increases the risk of HE 6.2 times (26). In contrast to OAC, the incidence of ICH in NonVitamin K oral anticoagulants (NOACs) patients is dramatically decreased (27). NOACs-ICH has a lower risk of developing HE and is associated with smaller baseline hematoma volume (28) and better functional outcomes (29-31).

Higher baseline NIHSS or GCS scores (32-34), elevated body temperature (35), baseline weight (36), and history of cerebral infarction (37) or alcohol abuse (38) may increase the risk of $\mathrm{HE}$, as found by some observational studies, and further randomized trials are needed to determine their relevance. In a recent retrospective cohort study of $\mathrm{ICH}$ patients with liver fibrosis, fibrosis-4 score and Aspartate Aminotransferase-Platelet Ratio Index were associated with HE (39).

Gender (40) and age (41) are also associated with HE, as men and older subjects (age $\geq 85$ years) are more likely to present HE than women and younger subjects $(40,41)$.

It is interesting to note that $\mathrm{ICH}$ occurring during the daytime tends to be more likely to present HE than when occurring at night (OR, 3.53) (42). In addition, HE is mostly found in early initial CT scan ( $\leq 3 \mathrm{~h}$ of onset) $(5,6,43)$, so time interval from ICH onset to initial CT scan should be considered (Abovementioned clinical predictors are summarized in Table 1).

\section{IMAGING PREDICTORS}

Some imaging phenomena that have been described in association with $\mathrm{HE}$ may have their origin in the 
TABLE 1 | Clinical predictors of HE.

\begin{tabular}{|c|c|c|c|c|c|c|}
\hline Clinical features & References & Country & $\begin{array}{l}\text { Sample } \\
\text { size }\end{array}$ & Baseline CT time & Follow-up CT time & Definition of HE \\
\hline SBP & Ohwaki et al. (18) & Japan & 76 & At admission & The day after admission & Absolute growth $>12.5 \mathrm{~mL}$, or relative growth of $>40 \%$ \\
\hline Prior APT & Toyoda et al. (22) & Japan & 251 & At admission & $24 \mathrm{~h}$ later after admission & Relative growth of $>40 \%$ \\
\hline Prior VKAs & Flibotte et al. (26) & America & 183 & At admission & Up to 7 days after admission & Relative growth of $>33 \%$ \\
\hline Prior NOACs & Takahashi et al. (30) & Japan & 78 & At admission & Within $24 \mathrm{~h}$ after baseline & - \\
\hline Gander & Marini et al. (40) & America & 2212 & Within $6 \mathrm{~h}$ of onset & Within $24 \mathrm{~h}$ after baseline & Absolute growth $>6 \mathrm{~mL}$, or relative growth of $>33 \%$ \\
\hline Age & Forti et al. (41) & Italy & 383 & Within $6 \mathrm{~h}$ of onset & Ranging $436 \mathrm{~h}$ after baseline & Absolute growth $>6 \mathrm{~mL}$, or relative growth of $>33 \%$ \\
\hline $\begin{array}{l}\text { Time from ICH } \\
\text { symptom onset }\end{array}$ & Kazui et al. (6) & Japan & 204 & Within $48 \mathrm{~h}$ of onset & t Within $120 \mathrm{~h}$ of onset & Absolute growth $>12.5 \mathrm{~mL}$, or relative growth of $>40 \%$ \\
\hline Day-night variability & Yao et al. (42) & America & 111 & Within $3 \mathrm{~h}$ of onset & Within $75 \mathrm{~h}$ of onset & Absolute growth $>6 \mathrm{~mL}$ or relative growth of $>33 \%$ \\
\hline
\end{tabular}

pathophysiological processes around the hematoma, caused, e.g., by the breakdown of the blood brain barrier after $\mathrm{ICH}$, which reflects the infiltration of blood into the peri-hematoma tissues and secondary damages resulting from the blood component such as albumin.

\section{CTA Predictors}

Based on increased penetration of contrast agent, Wada et al. first described the spot sign (44), a single or multiple focus of contrast enhancement in the hematoma, which is considered a risk factor of death and clinical neurological deterioration (45) and an independent predictor of HE with $51-62 \%$ sensitivity and $85-88 \%$ specificity in different clinical research centers $(8,45)$. Intriguingly, the numbers of spot sign predominantly determine the value of spot sign in predicting HE (46), while the positive predictive value of spot sign is inversely associated with $\mathrm{ICH}$ onset-to-CTA time, which may indicate the dynamic process of spot sign (43). With further studies, some modified spot signs of CT perfusion (CTP), venous phase CTA, post contrast CT (PCT), and 90-s delayed CTA have presented with higher sensitivity and specificity $(47,48)$. Considering the resemblance of blood vessels in the hematoma and spot sign, Yi et al. found that continuous CTA source images could exclude blood vessels and improve its accuracy in predicting HE (49).

The leakage sign and higher Iodine Concentration (IC) within spot sign have been found to increase its sensitivity and specificity. IC was demonstrated to be an important characteristic of the spot sign and combining higher IC (i.e., IC $>7.82,100 \mu \mathrm{g} / \mathrm{ml}$ ) with spot sign was an independent predictor of $\mathrm{HE}$ with sensitivity of up to 0.81 (50). The leakage sign which refers to a $1 \mathrm{~cm}$ diameter region of interest (ROI) and an increase of more than $10 \%$ in high Hounsfield unit (HU) in the ROI was proposed by Orito et al. and showed significantly higher sensitivity (93.3\%) and specificity (88.9\%) for predicting HE (51).

CTA spot sign and leakage sign can easily predict the HE, and CTA seems to be a good screening tool in detecting the secondary cause of the bleeding, the vascular malformations in $\mathrm{ICH}$ patients. However, its clinical practice is actually restricted by limited use of CTA, and there is a pressing need to discover more convenient imaging predictors in $\mathrm{ICH}$ patients.

\section{Non-contrast Computed Tomography (NCCT) Predictors}

There are three categories of NCCT predictors: the large initial volume, irregular shape, and heterogeneity of the hematoma (52). The first two are well-known for predicting HE (52-55). Density heterogeneity is more and more noteworthy nowadays and some signs have been discovered to suggest HE.

Blend sign (Figure 1), the blending of the hyperattenuating region with an adjacent relatively hypoattenuating area with a well-defined margin, was first found by $\mathrm{Li}$ et al. which is easy to use for predicting $\mathrm{HE}(56,57)$ and poor functional outcome (58) with 95.5\% specificity. Black hole sign (Figure 1), the round, oval, or rod-shaped relatively hypoattenuated area inside the hyperattenuated hematoma with a clear border with nearby brain tissue, is another NCCT predictor with 94.1\% specificity (59), which presents predictive accuracy for $\mathrm{HE}$ but is not an independent predictor of poor outcome compared with other NCCT features $(7,59,60)$. The island sign (Figure 1), three or more scattered small hematoma detached from the main hematomas, or more than 4 small hematomas connected partly or wholly to the main hematoma (61), is not only an appropriate shape-related predictor for HE, with $98.2 \%$ specificity, but also a novel imaging marker to predict long-standing poor prognosis (61-63). However, the three abovementioned NCCT signs presented with disappointing sensitivity (39.3\% of blend sign, $31.9 \%$ of black hole sign, and $44.7 \%$ of island sign), which dramatically decreases their practical clinical value. Later, satellite sign (Figure 1), which refers to high-density dots around the hematoma, was first put forward by Shimoda et al. and was demonstrated to be associated with large hemorrhage size (64). Recently, ICH patients presenting with high hematoma sedimentation levels, which may result from insufficient hemostasis, were predisposed to worse outcome in the study of Sato et al. (65). Other NCCT signs, such as hypodensities and the swirl sign (isodensity or hypodensity within a hyperdense area extending across 2 consecutive $5 \mathrm{~mm}$ axial CT sections), have also been proposed as predictors of HE $(66,67)$, but future clinical trials are needed to validate their predictive value in clinical practice. In addition to the descriptive signs, other researchers use quantitative methods to accurately measure the HU within the hematoma. Jeong et al. 


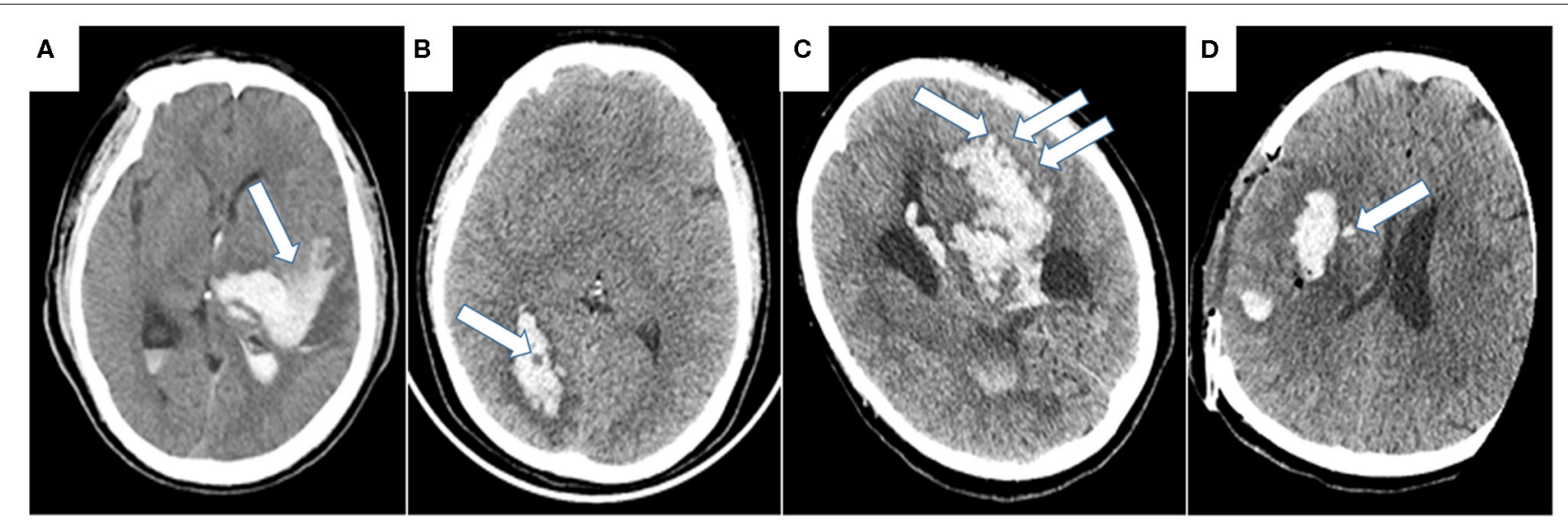

FIGURE 1 | Representative examples of NCCT markers of HE. (A) Blend sign refers to the blending of hyperattenuating region with adjacent relatively hypoattenuating area with a well-defined margin. (B) Black hole sign refers to the round, oval, or rod-shaped relatively hypoattenuated area inside the hyperattenuated hematoma with a clear border to nearby brain tissue. (C) Island sign refers to three or more scattered small hematoma detached from the main hematoma, or more than 4 small hematoma connected partly or wholly with the main hematoma. (D) Satellite sign refers to the high-density dots around the hematoma.

recently revealed that lower mean $\mathrm{HU}$ of a hematoma, which may be a clue of impaired clot contraction, is more likely to present HE (68). When minimal CT attenuation value in the hematoma is $<31 \mathrm{HU}$, the ICH patients is more likely to develop HE (69).

Before interpreting these NCCT predictors, there are several drawbacks to be found in the studies: (1) the definitions of $\mathrm{HE}$ are diverse; (2) most of the studies are derived from a small sample size in single center cohorts, which may increase the risk of selection bias; (3) several ICH patients, such as those with oral anticoagulant treatment, are excluded from enrollment narrowing clinical application. Thus, the use of these predictors in clinical settings warrants further multi-center studies with larger samples and uniform criterion to validate their predictive value. Moreover, the above-mentioned NCCT signs actually share similar features in identifying the physiopathologic changes in $\mathrm{HE}$, and if we can propose combined characteristics by integrating the terminology and diagnostic criteria of the NCCT predictors, it would be significant for predicting HE. Based on this hypothesis, an NCCT radiomics model, which was established from high-dimensional quantitative features of NCCT images, exhibited better predictive value on $\mathrm{HE}$ than a radiological model (70).

Although a few studies have compared the predictive effect of NCCT markers and CTA predictors $(71,72)$, we cannot conclude a distinct superiority of one predictor over the others due to their great heterogeneity in HE definition, terminology, and CTA acquisition protocol. In addition, even if there are several imaging predictors which are feasible for clinical practice, their application is largely constrained by lower sensitivity. Hence, a prediction score model combining two or more NCCT predictors, or clinical predictors or laboratory markers may increase the sensitivity and match the demand of clinical practice.

\section{Magnetic Resonance Imaging (MRI) Markers}

In clinical settings, ICH patients usually undergo MRI for etiological evaluation. In 1998, Murai et al. first reported MRI spot sign in $108 \mathrm{ICH}$ patients, which refers to the contrast extravasation within the hematoma. They found that MRI spot sign was closely associated with HE evidenced by follow-up CT scans (73). However, in a recent prospective study of $50 \mathrm{ICH}$ patients, MRI spot sign failed to have statistical significance in predicting $\mathrm{HE}$ (74). In addition to the conflicting results on $\mathrm{HE}$ prediction, it takes a long time to conduct an MRI scan and it is relatively expensive. Thus, the value of MRI imaging in predicting $\mathrm{HE}$ is limited.

\section{LABORATORY PREDICTORS}

\section{Coagulation Status}

In general, alteration of coagulation function is significant in those with coagulation dysfunction due to blood system diseases and antiplatelet or anticoagulant drugs use, not hypertension ICH patients; therefore, attention should be specifically paid to the former. In those patients, elevated D-dimer (D-D) level, decreased fibrinogen, and international normalized ratio (INR) $>1.5$ are found to be predictors of $\mathrm{HE}$ in multivariate analysis $(32,38)$. Moreover, coagulation factor deficiency due to liver dysfunction also increases the risk of developing $\mathrm{HE}(75,76)$.

\section{Blood Glucose}

More than $50 \%$ of stroke patients present with admission hyperglycemia (77), a result of abnormal energy metabolism in response to $\mathrm{ICH}$ at the acute stage. However, admission hyperglycemia is conversely correlated with poor functional outcomes and high fatality rates regardless of diabetes history $(78,79)$. Some recent observational studies validated that admission hyperglycemia is related to the imaging predictors of 
TABLE 2 | Comparison of prediction score models.

\begin{tabular}{|c|c|c|c|c|c|}
\hline & Creator & Time & Country & Sample size & C-statistic \\
\hline 3-predictor model & Ririko et al. & 2013 Jul & Japan & 201 & - \\
\hline 9-point score & Brouwers et al. & 2014 Feb & America & 817 & $0.72,0.77^{\star}$ \\
\hline 24-point score & Wang et al. & 2015 Feb & 21 countries & 964 & 0.73 \\
\hline PREDICT A/B score & Huynh et al. & 2015 Nov & 6 countries & 301 & - \\
\hline HEP score & Yao et al. & 2015 Oct & China & 237 & 0.76 \\
\hline Basal ganglia score & Huang et al. & $2017 \mathrm{Dec}$ & China & 266 & - \\
\hline BAT score & Morotti et al. & 2018 May & Several countries & 344 & $0.77,0.70^{\star}$ \\
\hline HEAVN scale & Miyahara et al. & 2018 Sep & Japan & 622 & $0.81,0.80^{*}$ \\
\hline 4-predictor model & Rustam et al. & 2018 Oct & - & - & 0.78 \\
\hline 5-predictor model & Rustam et al. & 2018 Oct & - & - & 0.83 \\
\hline NAG scale & Sakuta et al. & $2018 \mathrm{Dec}$ & Japan & 118 & 0.81 \\
\hline
\end{tabular}

*The former statistic for the development cohort, the latter statistic for the validation cohort.

HE, including island sign, spot sign, and blend sign (80-82). Moreover, a post-hoc analysis by Qureshi et al. in indicated that admission hyperglycemia increased the risk of developing $\mathrm{HE}$ 2.5-fold (83), which may be mediated by plasma kallikrein (84).

\section{Inflammation and Microvascular Integrity Markers}

Inflammation response to $\mathrm{ICH}$ is an important factor for developing $\mathrm{HE}$, which may lead to progressive damage of peri-hematoma vessels and continuation of bleeding. More research is revealing that high plasma concentrations of inflammatory factors, such as IL-6 ( $>24 \mathrm{pg} / \mathrm{ml})$, CRP ( $>10$ $\mathrm{mg} / \mathrm{L}$ ), and cellular fibronectin (c-Fn $>6 \mu \mathrm{g} / \mathrm{ml}$ ), are associated with $\mathrm{HE}$ (85-87). Specifically, the risk of $\mathrm{HE}$ in patients with high plasma concentrations of CRP, IL-6, and c-Fn, respectively, increase 4-, 16-, and 92-fold, respectively, compared with normal counterparts (85). Moreover, the elevated matrix metalloproteinase-9 (MMP-9) level, an important cause of blood brain barrier ( $\mathrm{BBB}$ ) breakdown in acute cerebrovascular events, is also an independent risk factor for $\operatorname{HE}$ (OR value 15.65$)(85,88)$.

\section{Others}

Low level of serum cholesterol, calcium, hemoglobin, or magnesium and high serum creatinine levels have also been reported to be correlated with $\mathrm{HE}$ in observational studies (36, 80, 89-93). In addition, variants of apolipoprotein E (APOE) predispose patients with lobar ICH to HE (94). As most of these biochemical indicators are commonly tested in clinical settings, the use of these potential predictors may largely facilitate clinical practice but further clinical trials are warranted.

\section{PREDICTION SCORE MODEL}

As the low sensitivity or specificity of one predictor limits the clinical practice of these predictors, combining more predictors to set up a prediction score system may be a solution to the problem. Based on univariate and multivariable logistic regression analysis, several prediction score systems have been established to predict the risk of HE (Table 2).
Based on clinical and imaging predictors, a practical prediction model was created comprised of hematoma volume, hematoma heterogeneity, and systolic BP $1.5 \mathrm{~h}$ after admission. However, further clinical trials are needed to validate its prediction value (95). Brouwers et al. later established a 9-point prediction score on four predictors: warfarin use, spot sign, time from ICH onset to the initial computed tomography, and baseline ICH volume, which demonstrated strong association with $\mathrm{HE}(\mathrm{OR}, 4.59)$ (96). Although prospectively collected data and large sample size in the study added robustness to the results, a high dropout rate of patients with prior warfarin use or large baseline hematoma volume led to an underestimation of the predictive ability. Considering that CTA is not always available in acute ICH, a 24-point score, which is derived from sub-studies of INTERACT1 and 2, removed CTA spot sign and added intraventricular hemorrhage (IVH) extension and recurrent ICH (97). Despite both 9-point and 24-point scores showing acceptable discrimination, their calibration remains to be improved. Two new scores, the PREDICT A and B score, were then created substituting GCS or NIHSS score for baseline ICH volume and showed improved discrimination (32). It is worth noting that the PREDICT scores are suited only to supratentorial ICH because infratentorial ICH was excluded and the cohort had a relatively small sample size; thus, they require further independent validation. Another new Hematoma Expansion Prediction (HEP) score added a history of dementia and smoking and showed satisfactory discrimination ability (C-statistics, 0.76) (98). Based on multivariable logistic regression analysis, a basal ganglia score adopted three NCCT markers (island sign, blend sign, and swirl sign) and demonstrated reliable accuracy in predicting HE $(P<0.001)$ (99). Furthermore, to further simplify the prediction at the bedside, three new scales (the BAT score, NAG scale, and HEAVN scale) which added more practical predictors have been established from retrospective studies and have shown acceptable sensitivity and specificity $(33,34,100$, 101), but prospective validations of these scores are warranted. In a patient-level meta-analysis, Al-Shahi et al. analyzed predictors from diverse cohorts with large sample size to develop $\mathrm{HE}$ prediction models using four (time from symptom onset to 
CT, baseline $\mathrm{ICH}$ volume, antiplatelet use, and anticoagulant use) or five predictors (with the addition of spot sign). Both prediction models were externally validated and showed good discrimination (102).

Although many prediction scores have been proposed, currently none of them can impact clinical decision-making. First, they are inconvenient in clinical practice and it is difficult for clinicians to fulfill the score in a short time. Second, most of the predictors in these scores were derived from retrospective studies and only a few scores were demonstrated in external prospective trials, which implies that their accuracy remains to be examined. Third, the majority of the studies collected date from small-sized cohorts in one single center, which increases the risk of selection bias and decreases their accuracy in predicting HE. In the future, scales combining convenience and accuracy should be established and confirmed in large external and prospective studies, which will greatly contribute to clinical HE prediction.

\section{PATHOPHYSIOLOGY}

HE was once conceptualized as a continuing or recurrent bleeding partly caused by coagulation dysfunction or hemodynamic instability, until Miller Fisher proposed an alternative "avalanche" model (103). Based on his study, early $\mathrm{HE}$ was related to secondary multifocal micro- and macroscopic bleeding into the peri-hematoma area due to the ischemia and congestion following ICH (104). Several later studies $(105,106)$ and analyses of CT and SPECT in ICH $(104,107)$ added supportive evidences for the hypothesis, and the postulated mechanisms underlying these phenomenon include: (1) local tissue distortion caused by increased intracranial pressure; (2) blood brain barrier breakdown due to matrix metalloproteinase (MMP) activation; (3) secondary inflammatory reaction related to promoted activation, chemotaxis, and differentiation of macrophages, lymphocytes, microglia, and other inflammatory cells (108-111). However, it is difficult to verify the hypothesis without $\mathrm{HE}$ animal models.

\section{MEDICAL TREATMENT FOR HE}

Although the treatment of HE remains a challenge, researchers persevere in exploring effective solutions. At present, the treatment of HE is mainly divided into blood pressure control, hemostatic treatment, glucose management, and others.

\section{INTENSIVE BLOOD PRESSURE-LOWERING TREATMENT}

Both INTERACT (112) and ATACH (113) have yielded safe and feasible intensive SBP lowering $(\leq 140 \mathrm{~mm} \mathrm{Hg})$ in $\mathrm{ICH}$. Moreover, subsequent INTERACT2 showed that intensive SBP lowering when obtained within the first hour and sustained throughout the first $24 \mathrm{~h}$ of $\mathrm{ICH}$ onset was related to reduced HE (114), specifically in basal ganglia ICH (15). However, the rate of mortality or disability was not decreased in intensive SBP lowering patients $(14,115)$, even in those with imaging predictors of HE $(116,117)$. This discrepancy may result from the neutralization effect that cardiorenal complications caused by intensive SBP lowering somehow diminished the benefits of suppressing HE $(118,119)$.

Substantial evidence has identified the presence of ischemic lesions both within and remote from the perihematoma region in ICH patients undergoing diffusion-weighted imaging (DWI) $(120,121)$. Intensive BP lowering may deteriorate the regional cerebral blood flow (CBF) after ICH and subsequently promote ischemic lesion formation. Studies have demonstrated that acute $\mathrm{BP}$ reductions after $\mathrm{ICH}$ is associated with decreased diffusion on DWI (122), and DWI-lesions are, in turn, correlated with poor functional outcomes (123). Thus, the presence of ischemic lesions may be a possible explanation for limited benefits after BP lowering in $\mathrm{ICH}$ patients.

Considering the potential side effects and yet improved functional outcomes of intensive BP reduction, the target goal of $\mathrm{BP}$ reduction, the optimal antihypertension drugs, and subgroup patients to the treatment are still problems. Recently target SBP of $130-139 \mathrm{mmHg}$ has been suggested to be the optimal goal in the initial $24 \mathrm{~h}$ of acute ICH in the follow-up analysis of both INTERACT-2 (124) and ATACH-2 (119), but the support of larger randomized trials is lacking. Of note, in view of

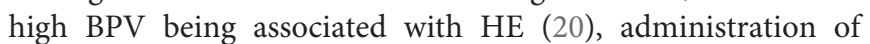
stable antihypertension drugs such as urapidil may result in better clinical outcomes and future studies should be conducted to compare different efficacies of antihypertension drugs in reducing $\mathrm{HE}$. In addition, as not all $\mathrm{ICH}$ patients can benefit from intensive SBP lowering, it is necessary to select subgroups of patients at high risk of developing HE. Actually, studies have shown that those ICH patients who presents with an early onset, higher initial SBP, prior anti-thrombotic therapy, or milder neurological dysfunction at baseline were found to be associated with better functional outcomes in rapid SBP lowering $(114,125,126)$. However, currently the characteristics of ICH patients benefiting from SBP control are still unclear and a complete screening scheme should be established to facilitate clinical practice in future studies.

To conclude, although intensive SBP lowering can reduce HE, not all patients can benefit from the therapy and further randomized clinical trials are needed to identify optimal patients for intensive SBP lowering treatment. Meanwhile, an appropriate target SBP level is essential for clinical decision-making and large prospective trials are needed to validate the proposed target SBP of $130-139 \mathrm{mmHg}$.

\section{HEMOSTATIC THERAPY}

Platelet transfusion was once considered feasible for thrombocytopenia or antiplatelet medication-related ICH. However, platelet transfusion showed no overall benefit in ICH patients under antiplatelet treatment (127) and cannot be recommended due to its conversely higher mortality and insufficient efficacy at 3 months (128-132), because platelet transfusion cannot be completed within $6 \mathrm{~h}$ of onset when hemostasis is finished in most ICH patients (128). Moreover, 
recent studies have demonstrated that reduced platelet activity was related to early HE $(133,134)$ and was more common than reported prior antiplatelet therapy in ICH patients (135), thus improving platelet activity (such as desmopressin treatment) (136) after ICH has the potential to decrease HE, but further randomized trials are needed to verify the effect.

$\mathrm{HE}$ is more likely to occur in anticoagulant related-ICH and reversal agents might play an important role in the treatment of these patients. Compared with three-factor prothrombin complex concentrate (PCC) and fresh-frozen plasma (FFP) (137, 138), four-factor PCC, which might decrease HE, should be first recommended to reverse the effect of OAC with a more rapid international normalized ratio (INR) reduction, a better effect, and fewer adverse events (139-144). Studies investigating hemostatic therapy to reduce $\mathrm{HE}$ in NOAC-associated ICH are lacking, but several NOAC antagonists have been found. Idarucizumab, Andexanet Alfa, and PER977 have a demonstrated effect on reversal of NOAC dabigatran, FXa inhibitors, and edoxaban, respectively, (145-151), but their effect on HE needs to be further studied.

Mayer et al. conducted two successive trials, Factor Seven For Hemorrhagic Stroke-1, 2 (FAST-1, 2), both of which demonstrated recombinant factor VIIa (RFVIIa), can reduce HE but showed opposite results in clinical outcomes $(152,153)$. Later, meta-analyses of these and other clinical trials documented no effect on improving survival or functional outcomes after ICH (154). A recently published work also revealed that rFVIIa administration within $3 \mathrm{~h}$ from stroke onset cannot benefit spot sign-positive ICH patients (155). Notably, an excess of thromboembolic events remains a concern in RFVIIa treatment (156). Notwithstanding, subsequent subgroup analysis revealed that highly selected individuals, younger than 70 years old or hemophilia A patients, could benefit from RFVIIa infusion $(157,158)$.

Another tested hemostatic drug is tranexamic acid (TXA), which reversibly inhibits the conversion of plasminogen to plasmin. Tranexamic acid for hyperacute primary Intracerebral Hemorrhage trial (TICH2) is an international, randomized placebo-controlled trial aimed at evaluating the effect of TXA on ICH and has demonstrated that TXA could reduce HE, but functional outcomes at 90 days after ICH were not improved $(9,159)$. Moreover, increased risk of ischemic events remains a problem (160). Thus, a sub-study of TICH-2 which specifically aims at whether spot sign-positive patients could benefit from TXA administration is currently under way (161).

Several hemostasis therapies, including platelet transfusion, reversal agents of anticoagulants, and none specific hemostatic drugs such as RFVIIa and TXA, have been recommended for patients with hemostatic abnormalities to prevent $\mathrm{HE}$ in ICH. Although hemostasis therapy is an effective intervention for ICH-patients who have HE within the treatment window, its clinical practice is limited by conversely adverse effects from the long-term recovery. Moreover, in most cases hemostasis therapy only applies to those patients with coagulation dysfunction, and significant effect cannot be yielded from hemostasis therapy in hypertension-related ICH patients. Thus, future studies should pay attention to selecting the optimal ICH patients for hemostasis therapy to improve the efficacy.

\section{GLUCOSE MANAGEMENT}

Admission hyperglycemia is a predictor of HE independent of the presence of diabetes mellitus, and Qureshi et al. revealed that glucose monitoring and control in a rational range is correlated with the reduction of $\mathrm{HE}$ (83). However, intensive serum glucose lowering should not be recommended because of the increased risk of hypoglycemic events and even mortality in these patients (162-164). However, a preclinical study has reported that $17 \beta$-estradiol (E2) can attenuate hyperglycemia-related HE and improve neurological function in mice (165). Given that the increase of blood glucose is actually the consequence of energy metabolism dysfunction in the acute phase of $\mathrm{ICH}$, the clinical value of short-term blood glucose control might be significant, but the target glucose level and the appropriate management to control glucose in ICH patients remains to be clarified.

\section{OTHERS}

A serials of preclinical researches of MMP inhibitors like CM352 (88, 166-168), and neuroprotectors such as NXY-059 (169, 170), NSP-116 (171), erythropoietin (172), valproic acid (173), memantine (174), curcumin (175), albumin (176), and tuftsin fragment 1-3 (177) have shed light on the treatment of HE. However, further studies to confirm the effect of CM352 and neuroprotectors are needed, since some pre-clinic medicines failed in clinical trials. For e.g., the Cerebral Hematoma And NXY Treatment trial (CHANT) has revealed that there is no effect of NXY-059 on the size of hematoma (170).

In conclusion, HE is a complex and dynamic process during ICH with poor functional prognosis. In consideration of the limited effect, we need to identify subgroup ICH patients who can benefit from the decrease of $\mathrm{HE}$ and therapies should give priority to those selected patients. Furthermore, individual characteristics such as age, hypertension history, intracranial pressure, and anticoagulant use should be taken into consideration when making decisions to treat HE. There is no appropriate animal model of HE, which limits the basic research and the discovery of new treatment target for HE. Thus, the discovery of a novel animal model which can mimic the natural process of ICH in humans would have a significant meaning.

\section{AUTHOR CONTRIBUTIONS}

$\mathrm{ZL}$ and MY was responsible for conception and design as well as initial drafting of the manuscript. CL and RB were responsible for revising the manuscript. HX was responsible for tables and figures. $\mathrm{QH}$ and $\mathrm{BH}$ read and approved the final manuscript.

\section{FUNDING}

This work was supported by National Key Research \& Development Program of China (Grant No. 2018YFC1312200 to $\mathrm{BH}$ ), National Natural Science Foundation of China (Grant No. 81571119 to BH, Grant No. 81400969 to QH). 


\section{REFERENCES}

1. Qureshi AI, Mendelow AD, Hanley DF. Intracerebral haemorrhage. Lancet. (2009) 373:1632-44. doi: 10.1016/S0140-6736(09)60371-8

2. An SJ, Kim TJ, Yoon BW. Epidemiology, risk factors, and clinical features of intracerebral hemorrhage: an update. J Stroke. (2017) 19:3-10. doi: 10.5853/jos.2016.00864

3. Rodriguez-Luna D, Coscojuela P, Rodriguez-Villatoro N, Juega JM, Boned S, Muchada M, et al. Multiphase CT angiography improves prediction of intracerebral hemorrhage expansion. Radiology. (2017) 285:932-40. doi: 10.1148/radiol.2017162839

4. Fujii Y, Tanaka R, Takeuchi S, Koike T, Minakawa T, Sasaki O. Hematoma enlargement in spontaneous intracerebral hemorrhage. J Neurosurg. (1994) 80:51-7. doi: 10.3171/jns.1994.80.1.0051

5. Brott T, Broderick J, Kothari R, Barsan W, Tomsick T, Sauerbeck L, et al. Early hemorrhage growth in patients with intracerebral hemorrhage. Stroke. (1997) 28:1-5. doi: 10.1161/01.STR.28.1.1

6. Kazui S, Naritomi H, Yamamoto H, Sawada T, Yamaguchi T. Enlargement of spontaneous intracerebral hemorrhage. Incidence and time course. Stroke. (1996) 27:1783-7. doi: 10.1161/01.STR.27.10.1783

7. He GN, Guo HZ, Han X, Wang EF, Zhang YQ. Comparison of CT black hole sign and other CT features in predicting hematoma expansion in patients with ICH. J Neurol. (2018) 265:1883-90. doi: 10.1007/s00415-018-8932-6

8. Demchuk AM, Dowlatshahi D, Rodriguez-Luna D, Molina CA, Blas YS, Dzialowski I, et al. Prediction of haematoma growth and outcome in patients with intracerebral haemorrhage using the CT-angiography spot sign (PREDICT): a prospective observational study. Lancet Neurol. (2012) 11:307-14. doi: 10.1016/S1474-4422(12)70038-8

9. Sprigg N, Flaherty K, Appleton JP, Al-Shahi Salman R, Bereczki D, Beridze $\mathrm{M}$, et al. Tranexamic acid for hyperacute primary IntraCerebral Haemorrhage (TICH-2): an international randomised, placebocontrolled, phase 3 superiority trial. Lancet. (2018) 391:2107-15. doi: 10.1016/S0140-6736(18)31033-X

10. Delgado Almandoz JE, Yoo AJ, Stone MJ, Schaefer PW, Goldstein JN, Rosand J, et al. Systematic characterization of the computed tomography angiography spot sign in primary intracerebral hemorrhage identifies patients at highest risk for hematoma expansion: the spot sign score. Stroke. (2009) 40:2994-3000. doi: 10.1161/STROKEAHA.109.554667

11. Thompson AL, Kosior JC, Gladstone DJ, Hopyan JJ, Symons SP, Romero F, et al. Defining the CT angiography 'spot sign' in primary intracerebral hemorrhage. Can J Neurol Sci. (2009) 36:456-61. doi: 10.1017/S0317167100007782

12. Dowlatshahi D, Demchuk AM, Flaherty ML, Ali M, Lyden PL, Smith EE. Defining hematoma expansion in intracerebral hemorrhage: relationship with patient outcomes. Neurology. (2011) 76:1238-44. doi: 10.1212/WNL.0b013e3182143317

13. Yogendrakumar V, Ramsay T, Fergusson DA, Demchuk AM, Aviv RI, Rodriguez-Luna $\mathrm{D}$, et al. Redefining hematoma expansion with the inclusion of intraventricular hemorrhage growth. Stroke. (2020) 51:1120-7. doi: 10.1161/STROKEAHA.119.027451

14. Anderson CS, Heeley E, Huang Y, Wang J, Stapf C, Delcourt C, et al. Rapid blood-pressure lowering in patients with acute intracerebral hemorrhage. N Engl J Med. (2013) 368:2355-65. doi: 10.1056/NEJMoa 1214609

15. Leasure AC, Qureshi AI, Murthy SB, Kamel H, Goldstein JN, Woo D, et al. Association of intensive blood pressure reduction with risk of hematoma expansion in patients with deep intracerebral hemorrhage. JAMA Neurol. (2019) 76:949-55. doi: 10.1001/jamaneurol.2019.1141

16. Rodriguez-Luna D, Rodriguez-Villatoro N, Juega JM, Boned S, Muchada M, Sanjuan E, et al. Prehospital systolic blood pressure is related to intracerebral hemorrhage volume on admission. Stroke. (2018) 49:204-6. doi: 10.1161/STROKEAHA.117.018485

17. Maruishi M, Shima T, Okada Y, Nishida M, Yamane K. Involvement of fluctuating high blood pressure in the enlargement of spontaneous intracerebral hematoma. Neurol Med Chir. (2001) 41:300-4; discussion: 304-5. doi: 10.2176/nmc.41.300

18. Ohwaki K, Yano E, Nagashima H, Hirata M, Nakagomi T, Tamura A. Blood pressure management in acute intracerebral hemorrhage: relationship between elevated blood pressure and hematoma enlargement. Stroke. (2004) 35:1364-7. doi: 10.1161/01.STR.0000128795.38283.4b

19. Rodriguez-Luna D, Pineiro S, Rubiera M, Ribo M, Coscojuela P, Pagola J, et al. Impact of blood pressure changes and course on hematoma growth in acute intracerebral hemorrhage. Eur J Neurol. (2013) 20:1277-83. doi: 10.1111/ene.12180

20. Buratti L, Cagnetti C, Balucani C, Viticchi G, Falsetti L, Luzzi S, et al. Blood pressure variability and stroke outcome in patients with internal carotid artery occlusion. J Neurol Sci. (2014) 339:164-8. doi: 10.1016/j.jns.2014.02.007

21. Lovelock CE, Molyneux AJ, Rothwell PM. Change in incidence and aetiology of intracerebral haemorrhage in Oxfordshire, UK, between 1981 and 2006: a population-based study. Lancet Neurol. (2007) 6:487-93. doi: $10.1016 /$ S1474-4422(07)70107-2

22. Toyoda K, Okada Y, Minematsu K, Kamouchi M, Fujimoto S, Ibayashi S, et al. Antiplatelet therapy contributes to acute deterioration of intracerebral hemorrhage. Neurology. (2005) 65:1000-4. doi: 10.1212/01.wnl.0000179178.37713.69

23. Sansing LH, Messe SR, Cucchiara BL, Cohen SN, Lyden PD, Kasner SE. Prior antiplatelet use does not affect hemorrhage growth or outcome after ICH. Neurology. (2009) 72:1397-402. doi: 10.1212/01.wnl.0000342709.31341.88

24. Camps-Renom P, Alejaldre-Monforte A, Delgado-Mederos R, MartinezDomeno A, Prats-Sanchez L, Pascual-Goni E, et al. Does prior antiplatelet therapy influence hematoma volume and hematoma growth following intracerebral hemorrhage? Results from a prospective study and a metaanalysis. Eur J Neurol. (2017) 24:302-8. doi: 10.1111/ene.13193

25. Flaherty ML, Tao H, Haverbusch M, Sekar P, Kleindorfer D, Kissela B, et al. Warfarin use leads to larger intracerebral hematomas. Neurology. (2008) 71:1084-9. doi: 10.1212/01.wnl.0000326895.58992.27

26. Flibotte JJ, Hagan N, O'Donnell J, Greenberg SM, Rosand J. Warfarin, hematoma expansion, and outcome of intracerebral hemorrhage. Neurology. (2004) 63:1059-64. doi: 10.1212/01.WNL.0000138428.40673.83

27. Chatterjee S, Sardar P, Biondi-Zoccai G, Kumbhani DJ. New oral anticoagulants and the risk of intracranial hemorrhage: traditional and Bayesian meta-analysis and mixed treatment comparison of randomized trials of new oral anticoagulants in atrial fibrillation. JAMA Neurol. (2013) 70:1486-90. doi: 10.1001/jamaneurol.2013.4021

28. Tsivgoulis G, Lioutas VA, Varelas P, Katsanos AH, Goyal N, Mikulik $\mathrm{R}$, et al. Direct oral anticoagulant- vs vitamin $\mathrm{K}$ antagonist-related nontraumatic intracerebral hemorrhage. Neurology. (2017) 89:1142-51. doi: 10.1212/WNL.0000000000004362

29. Hagii J, Tomita H, Metoki N, Saito S, Shiroto H, Hitomi H, et al. Characteristics of intracerebral hemorrhage during rivaroxaban treatment: comparison with those during warfarin. Stroke. (2014) 45:2805-7. doi: 10.1161/STROKEAHA.114.006661

30. Takahashi H, Jimbo Y, Takano H, Abe H, Sato M, Fujii Y, et al. Intracerebral hematoma occurring during warfarin versus non-vitamin $\mathrm{K}$ antagonist oral anticoagulant therapy. Am J Cardiol. (2016) 118:222-5. doi: 10.1016/j.amjcard.2016.04.034

31. Inohara $T$, Xian $Y$, Liang L, Matsouaka RA, Saver JL, Smith EE, et al. Association of intracerebral hemorrhage among patients taking non-vitamin $\mathrm{K}$ antagonist vs vitamin $\mathrm{K}$ antagonist oral anticoagulants with in-hospital mortality. JAMA. (2018) 319:463-73. doi: 10.1001/jama.2017.21917

32. Huynh TJ, Aviv RI, Dowlatshahi D, Gladstone DJ, Laupacis A, Kiss A, et al. Validation of the 9-point and 24-point hematoma expansion prediction scores and derivation of the PREDICT A/B scores. Stroke. (2015) 46:3105-10. doi: 10.1161/STROKEAHA.115.009893

33. Miyahara M, Noda R, Yamaguchi S, Tamai $Y$, Inoue $M$, Okamoto $K$, et al. New prediction score for hematoma expansion and neurological deterioration after spontaneous intracerebral hemorrhage: a hospital-based retrospective cohort study. J Stroke Cerebrovasc Dis. (2018) 27:2543-50. doi: 10.1016/j.jstrokecerebrovasdis.2018.05.018

34. Sakuta K, Sato T, Komatsu T, Sakai K, Terasawa Y, Mitsumura H, et al. The NAG scale: noble predictive scale for hematoma expansion in intracerebral hemorrhage. J Stroke Cerebrovasc Dis. (2018) 27:2606-12. doi: 10.1016/j.jstrokecerebrovasdis.2018.05.020

35. Leira R, Davalos A, Silva Y, Gil-Peralta A, Tejada J, Garcia M, et al. Early neurologic deterioration in intracerebral hemorrhage: 
predictors and associated factors. Neurology. (2004) 63:461-7. doi: 10.1212/01.WNL.0000133204.81153.AC

36. Broderick JP, Diringer MN, Hill MD, Brun NC, Mayer SA, Steiner T, et al. Determinants of intracerebral hemorrhage growth: an exploratory analysis. Stroke. (2007) 38:1072-5. doi: 10.1161/01.STR.0000258078.35316.30

37. Kazui S, Minematsu K, Yamamoto H, Sawada T, Yamaguchi T. Predisposing factors to enlargement of spontaneous intracerebral hematoma. Stroke. (1997) 28:2370-5. doi: 10.1161/01.STR.28.12.2370

38. Fujii Y, Takeuchi S, Sasaki O, Minakawa T, Tanaka R. Multivariate analysis of predictors of hematoma enlargement in spontaneous intracerebral hemorrhage. Stroke. (1998) 29:1160-6. doi: 10.1161/01.STR.29.6. 1160

39. Parikh NS, Kamel H, Navi BB, Iadecola C, Merkler AE, Jesudian A, et al. Liver fibrosis indices and outcomes after primary intracerebral hemorrhage. Stroke. (2020) 51:830-7. doi: 10.1161/STROKEAHA.119.028161

40. Marini S, Morotti A, Ayres AM, Crawford K, Kourkoulis CE, Lena UK, et al. Sex differences in intracerebral hemorrhage expansion and mortality. J Neurol Sci. (2017) 379:112-6. doi: 10.1016/j.jns.2017.05.057

41. Forti P, Maioli F, Domenico Spampinato M, Barbara C, Nativio V, Coveri $\mathrm{M}$, et al. The effect of age on characteristics and mortality of intracerebral hemorrhage in the oldest-old. Cerebrovasc Dis. (2016) 42:48592. doi: $10.1159 / 000448813$

42. Yao X, Wu B, Xu Y, Siwila-Sackman E, Selim M. Day-night variability of hematoma expansion in patients with spontaneous intracerebral hemorrhage. J Biol Rhythms. (2015) 30:242-50. doi: $10.1177 / 0748730415581489$

43. Dowlatshahi D, Brouwers HB, Demchuk AM, Hill MD, Aviv RI, Ufholz LA, et al. Predicting intracerebral hemorrhage growth with the spot sign: the effect of onset-to-scan time. Stroke. (2016) 47:695-700. doi: 10.1161/STROKEAHA.115.012012

44. Wada R, Aviv RI, Fox AJ, Sahlas DJ, Gladstone DJ, Tomlinson G, et al. CT angiography "spot sign" predicts hematoma expansion in acute intracerebral hemorrhage. Stroke. (2007) 38:1257-62. doi: 10.1161/01.STR.0000259633.59404.f3

45. Xu X, Zhang J, Yang K, Wang Q, Xu B, Chen X. Accuracy of spot sign in predicting hematoma expansion and clinical outcome: a meta-analysis. Medicine. (2018) 97:e11945. doi: 10.1097/MD.0000000000011945

46. Huynh TJ, Demchuk AM, Dowlatshahi D, Gladstone DJ, Krischek O, Kiss A, et al. Spot sign number is the most important spot sign characteristic for predicting hematoma expansion using first-pass computed tomography angiography: analysis from the PREDICT study. Stroke. (2013) 44:972-7. doi: 10.1161/STROKEAHA.111.000410

47. Koculym A, Huynh TJ, Jakubovic R, Zhang L, Aviv RI. CT perfusion spot sign improves sensitivity for prediction of outcome compared with CTA and postcontrast CT. AJNR Am J Neuroradiol. (2013) 34:965-70. doi: 10.3174/ajnr.A3338

48. Ciura VA, Brouwers HB, Pizzolato R, Ortiz CJ, Rosand J, Goldstein $\mathrm{JN}$, et al. Spot sign on 90-second delayed computed tomography angiography improves sensitivity for hematoma expansion and mortality: prospective study. Stroke. (2014) 45:3293-7. doi: 10.1161/STROKEAHA.114. 005570

49. Yi $\mathrm{P}, \mathrm{Xu} \mathrm{M}$, Chen $\mathrm{P}$, Luo $\mathrm{Y}$, Wang $\mathrm{D}$, Wang $\mathrm{H}$, et al. Eliminating vascular interference from the spot sign contributes to predicting hematoma expansion in individuals with spontaneous cerebral hemorrhages. Acta Neurol Belg. (2019). doi: 10.1007/s13760-019-01244-x. [Epub ahead of print].

50. Fu F, Sun S, Liu L, Li J, Su Y, Li Y. Iodine concentration: a new, important characteristic of the spot sign that predicts haematoma expansion. Eur Radiol. (2018) 28:4343-9. doi: 10.1007/s00330-01 8-5415-1

51. Orito K, Hirohata M, Nakamura Y, Takeshige N, Aoki T, Hattori $\mathrm{G}$, et al. Leakage sign for primary intracerebral hemorrhage: a novel predictor of hematoma growth. Stroke. (2016) 47:958-63. doi: 10.1161/STROKEAHA.115.011578

52. Blacquiere D, Demchuk AM, Al-Hazzaa M, Deshpande A, Petrcich $\mathrm{W}$, Aviv RI, et al. Intracerebral hematoma morphologic appearance on noncontrast computed tomography predicts significant hematoma expansion. Stroke. (2015) 46:3111-6. doi: 10.1161/STROKEAHA.115. 010566
53. Broderick JP, Brott TG, Duldner JE, Tomsick T, Huster G. Volume of intracerebral hemorrhage. A powerful and easy-to-use predictor of 30-day mortality. Stroke. (1993) 24:987-93. doi: 10.1161/01.STR.24.7.987

54. Dowlatshahi D, Smith EE, Flaherty ML, Ali M, Lyden P, Demchuk $\mathrm{AM}$, et al. Small intracerebral haemorrhages are associated with less haematoma expansion and better outcomes. Int J Stroke. (2011) 6:201-6. doi: 10.1111/j.1747-4949.2010.00563.x

55. Boulouis G, Morotti A, Charidimou A, Dowlatshahi D, Goldstein JN. Noncontrast computed tomography markers of intracerebral hemorrhage expansion. Stroke. (2017) 48:1120-5. doi: 10.1161/STROKEAHA.116.015062

56. Li Q, Zhang G, Huang YJ, Dong MX, Lv FJ, Wei X, et al. Blend sign on computed tomography: novel and reliable predictor for early hematoma growth in patients with intracerebral hemorrhage. Stroke. (2015) 46:2119-23. doi: 10.1161/STROKEAHA.115.009185

57. Lei C, Geng J, Chen C, Chang X. Accuracy of the blend sign on computed tomography as a predictor of hematoma growth after spontaneous intracerebral hemorrhage: a systematic review. J Stroke Cerebrovasc Dis. (2018) 27:1705-10. doi: 10.1016/j.jstrokecerebrovasdis.2018.01.032

58. Sporns PB, Schwake M, Schmidt R, Kemmling A, Minnerup J, Schwindt $\mathrm{W}$, et al. Computed tomographic blend sign is associated with computed tomographic angiography spot sign and predicts secondary neurological deterioration after intracerebral hemorrhage. Stroke. (2017) 48:131-5. doi: 10.1161/STROKEAHA.116.014068

59. Li Q, Zhang G, Xiong X, Wang XC, Yang WS, Li KW, et al. Black hole sign: novel imaging marker that predicts hematoma growth in patients with intracerebral hemorrhage. Stroke. (2016) 47:1777-81. doi: 10.1161/STROKEAHA.116.013186

60. Yu Z, Zheng J, Ma L, Guo R, Li M, Wang X, et al. The predictive accuracy of the black hole sign and the spot sign for hematoma expansion in patients with spontaneous intracerebral hemorrhage. Neurol Sci. (2017) 38:1591-7. doi: 10.1007/s10072-017-3006-6

61. Li Q, Liu QJ, Yang WS, Wang XC, Zhao LB, Xiong X, et al. Island sign: an imaging predictor for early hematoma expansion and poor outcome in patients with intracerebral hemorrhage. Stroke. (2017) 48:3019-25. doi: 10.1161/STROKEAHA.117.017985

62. Zhang F, Li H, Qian J, Zhang S, Tao C, You C, et al. Island sign predicts longterm poor outcome and mortality in patients with intracerebral hemorrhage. World Neurosurg. (2018) 120:e304-12. doi: 10.1016/j.wneu.2018.08.056

63. Yu Z, Zheng J, Li M, Wang X, Guo R, Ma L, et al. Determining the optimal shape-related indicator on noncontrast computed tomography for predicting hematoma expansion in spontaneous intracerebral hemorrhage. World Neurosurg. (2019) 121:e584-8. doi: 10.1016/j.wneu.2018.09.172

64. Shimoda Y, Ohtomo S, Arai H, Okada K, Tominaga T. Satellite sign: a poor outcome predictor in intracerebral hemorrhage. Cerebrovasc Dis. (2017) 44:105-12. doi: 10.1159/000477179

65. Sato S, Delcourt C, Zhang S, Arima H, Heeley E, Zheng D, et al. Determinants and prognostic significance of hematoma sedimentation levels in acute intracerebral hemorrhage. Cerebrovasc Dis. (2016) 41:80-6. doi: $10.1159 / 000442532$

66. Boulouis G, Morotti A, Brouwers HB, Charidimou A, Jessel MJ, Auriel E, et al. Association between hypodensities detected by computed tomography and hematoma expansion in patients with intracerebral hemorrhage. JAMA Neurol. (2016) 73:961-8. doi: 10.1001/jamaneurol.2016.1218

67. Ng D, Churilov L, Mitchell P, Dowling R, Yan B. The CT swirl sign is associated with hematoma expansion in intracerebral hemorrhage. Am J Neuroradiol. (2018) 39:232-7. doi: 10.3174/ajnr.A5465

68. Jeong HG, Bang JS, Kim BJ, Bae HJ, Han MK. Hematoma hounsfield units and expansion of intracerebral hemorrhage: a potential marker of hemostatic clot contraction. Int J Stroke. (2020). doi: 10.1177/1747493019895703. [Epub ahead of print].

69. Chu H, Huang C, Dong J, Yang X, Xiang J, Mao Y, et al. Minimal computed tomography attenuation value within the hematoma is associated with hematoma expansion and poor outcome in intracerebral hemorrhage patients. Neurocrit Care. (2019) 31:455-65. doi: 10.1007/s12028-019-00754-Z

70. Xie H, Ma S, Wang X, Zhang X. Noncontrast computer tomographybased radiomics model for predicting intracerebral hemorrhage expansion: preliminary findings and comparison with conventional radiological model. Eur Radiol. (2020) 30:87-98. doi: 10.1007/s00330-019-06378-3 
71. Sporns PB, Schwake M, Kemmling A, Minnerup J, Schwindt W, Niederstadt $\mathrm{T}$, et al. Comparison of spot sign, blend sign and black hole sign for outcome prediction in patients with intracerebral hemorrhage. J Stroke. (2017) 19:333-9. doi: 10.5853/jos.2016.02061

72. Zheng J, Yu Z, Xu Z, Li M, Wang X, Lin S, et al. The accuracy of the spot sign and the blend sign for predicting hematoma expansion in patients with spontaneous intracerebral hemorrhage. Med Sci Monit. (2017) 23:2250-7. doi: 10.12659/MSM.901583

73. Murai Y, Ikeda Y, Teramoto A, Tsuji Y. Magnetic resonance imagingdocumented extravasation as an indicator of acute hypertensive intracerebral hemorrhage. J Neurosurg. (1998) 88:650-5. doi: 10.3171/jns.1998.88.4.0650

74. Schindlbeck KA, Santaella A, Galinovic I, Krause T, Rocco A, Nolte $\mathrm{CH}$, et al. Spot sign in acute intracerebral hemorrhage in dynam T1-weighted magnetic resonance imaging. Stroke. (2016) 47:417-23. doi: 10.1161/STROKEAHA.115.011570

75. Niizuma H, Shimizu Y, Nakasato N, Jokura H, Suzuki J. Influence of liver dysfunction on volume of putaminal hemorrhage. Stroke. (1988) 19:987-90. doi: 10.1161/01.STR.19.8.987

76. Fujii Y, Takeuchi S, Tanaka R, Koike T, Sasaki O, Minakawa T. Liver dysfunction in spontaneous intracerebral hemorrhage. Neurosurgery. (1994) 35:592-6. doi: 10.1097/00006123-199410000-00003

77. Scott JF, Robinson GM, French JM, O’Connell JE, Alberti KG, Gray CS. Prevalence of admission hyperglycaemia across clinical subtypes of acute stroke. Lancet. (1999) 353:376-7. doi: 10.1016/S0140-6736(05)74948-5

78. Fogelholm R, Murros K, Rissanen A, Avikainen S. Admission blood glucose and short term survival in primary intracerebral haemorrhage: a population based study. J Neurol Neurosurg Psychiatry. (2005) 76:349-53. doi: 10.1136/jnnp.2003.034819

79. Koga M, Yamagami H, Okuda S, Okada Y, Kimura K, Shiokawa Y, et al. Blood glucose levels during the initial $72 \mathrm{~h}$ and 3 -month functional outcomes in acute intracerebral hemorrhage: the SAMURAI-ICH study. J Neurol Sci. (2015) 350:75-8. doi: 10.1016/j.jns.2015.02.018

80. Zhang F, Li H, Qian J, Tao C, Zheng J, You C, et al. Hyperglycemia predicts blend sign in patients with intracerebral hemorrhage. Med Sci Monit. (2018) 24:6237-44. doi: 10.12659/MSM.910024

81. Zhang F, Li H, Qian J, Zhang S, Tao C, You C, et al. Hyperglycemia is associated with island sign in patients with intracerebral hemorrhage. World Neurosurg. (2018) 119:e703-9. doi: 10.1016/j.wneu.2018.07.251

82. Zhang F, Zhang S, Tao C, Yang Z, Li X, You C, et al. Association between serum glucose level and spot sign in intracerebral hemorrhage. Medicine. (2019) 98:e14748. doi: 10.1097/MD.0000000000014748

83. Qureshi AI, Palesch YY, Martin R, Novitzke J, Cruz-Flores S, Ehtisham A, et al. Association of serum glucose concentrations during acute hospitalization with hematoma expansion, perihematomal edema, and three month outcome among patients with intracerebral hemorrhage. Neurocrit Care. (2011) 15:428-35. doi: 10.1007/s12028-011-9541-8

84. Liu J, Gao BB, Clermont AC, Blair P, Chilcote TJ, Sinha S, et al. Hyperglycemia-induced cerebral hematoma expansion is mediated by plasma kallikrein. Nat Med. (2011) 17:206-10. doi: 10.1038/nm.2295

85. Silva Y, Leira R, Tejada J, Lainez JM, Castillo J, Davalos A. Molecular signatures of vascular injury are associated with early growth of intracerebral hemorrhage. Stroke. (2005) 36:86-91. doi: 10.1161/01.STR.0000149615.51204.0b

86. Kuhlmann CR, Librizzi L, Closhen D, Pflanzner T, Lessmann $\mathrm{V}$, Pietrzik CU, et al. Mechanisms of C-reactive protein-induced blood-brain barrier disruption. Stroke. (2009) 40:1458-66. doi: 10.1161/STROKEAHA.108.535930

87. Di Napoli M, Parry-Jones AR, Smith CJ, Hopkins SJ, Slevin M, Masotti L, et al. C-reactive protein predicts hematoma growth in intracerebral hemorrhage. Stroke. (2014) 45:59-65. doi: 10.1161/STROKEAHA.113.001721

88. Yang Q, Zhuang X, Peng F, Zheng W. Relationship of plasma matrix metalloproteinase-9 and hematoma expansion in acute hypertensive cerebral hemorrhage. Int J Neurosci. (2016) 126:213-8. doi: 10.3109/00207454.2015.1007372

89. Takahashi H, Urano T, Nagai N, Takada Y, Takada A. Progressive expansion of hypertensive intracerebral hemorrhage by coagulopathy. Am J Hematol. (1998) 59:110-4. doi: 10.1002/(SICI)1096-8652(199810)59:2<110::AID-AJH2>3.0.CO;2-0

90. Liotta EM, Prabhakaran S, Sangha RS, Bush RA, Long AE, Trevick SA, et al. Magnesium, hemostasis, and outcomes in patients with intracerebral hemorrhage. Neurology. (2017) 89:813-9. doi: 10.1212/WNL.0000000000004249

91. Wang G, Zhang J. Hematoma expansion: clinical and molecular predictors and corresponding pharmacological treatment. Curr Drug Targets. (2017) 18:1367-76. doi: 10.2174/1389450117666160712092224

92. Jafari M, Di Napoli M, Datta YH, Bershad EM, Divani AA. The role of serum calcium level in intracerebral hemorrhage hematoma expansion: is there any? Neurocrit Care. (2018) 31:188-95. doi: 10.1007/s12028-018-0564-2

93. Roh DJ, Albers DJ, Magid-Bernstein J, Doyle K, Hod E, Eisenberger A, et al. Low hemoglobin and hematoma expansion after intracerebral hemorrhage. Neurology. (2019) 381:1279-81. doi: 10.1212/WNL.0000000000007820

94. Biffi A, Sonni A, Anderson CD, Kissela B, Jagiella JM, Schmidt H, et al. Variants at APOE influence risk of deep and lobar intracerebral hemorrhage. Ann Neurol. (2010) 68:934-43. doi: 10.1002/ana.22134

95. Takeda R, Ogura T, Ooigawa H, Fushihara G, Yoshikawa S, Okada D, et al. A practical prediction model for early hematoma expansion in spontaneous deep ganglionic intracerebral hemorrhage. Clin Neurol Neurosurg. (2013) 115:1028-31. doi: 10.1016/j.clineuro.2012.10.016

96. Brouwers HB, Chang Y, Falcone GJ, Cai X, Ayres AM, Battey TW, et al. Predicting hematoma expansion after primary intracerebral hemorrhage. JAMA Neurol. (2014) 71:158-64. doi: 10.1001/jamaneurol.2013.5433

97. Wang X, Arima H, Al-Shahi Salman R, Woodward M, Heeley E, Stapf $\mathrm{C}$, et al. Clinical prediction algorithm (BRAIN) to determine risk of hematoma growth in acute intracerebral hemorrhage. Stroke. (2015) 46:37681. doi: 10.1161/STROKEAHA.114.006910

98. Yao X, Xu Y, Siwila-Sackman E, Wu B, Selim M. The HEP score: a nomogram-derived hematoma expansion prediction scale. Neurocrit Care. (2015) 23:179-87. doi: 10.1007/s12028-015-0147-4

99. Huang Y, Zhang Q, Yang M. A reliable grading system for prediction of hematoma expansion in intracerebral hemorrhage in the basal ganglia. Biosci Trends. (2018) 12:193-200. doi: 10.5582/bst.2018.01061

100. Morotti A, Dowlatshahi D, Boulouis G, Al-Ajlan F, Demchuk AM, Aviv RI, et al. Predicting intracerebral hemorrhage expansion with noncontrast computed tomography: the BAT score. Stroke. (2018) 49:11639. doi: 10.1161/STROKEAHA.117.020138

101. Poli L, Leuci E, Costa P, De Giuli V, Caria F, Candeloro E, et al. Validation and comparison of noncontrast CT scores to predict intracerebral hemorrhage expansion. Neurocrit Care. (2019) 32:804-11. doi: 10.1007/s12028-019-00797-2

102. Al-Shahi Salman R, Frantzias J, Lee RJ, Lyden PD, Battey TWK, Ayres AM, et al. Absolute risk and predictors of the growth of acute spontaneous intracerebral haemorrhage: a systematic review and metaanalysis of individual patient data. Lancet Neurol. (2018) 17:885-94. doi: 10.1016/S1474-4422(18)30253-9

103. Fisher CM. Pathological observations in hypertensive cerebral hemorrhage. J Neuropathol Exp Neurol. (1971) 30:536-50. doi: 10.1097/00005072-197107000-00015

104. Mayer SA, Lignelli A, Fink ME, Kessler DB, Thomas CE, Swarup $\mathrm{R}$, et al. Perilesional blood flow and edema formation in acute intracerebral hemorrhage: a SPECT study. Stroke. (1998) 29:1791-8. doi: 10.1161/01.STR.29.9.1791

105. Greenberg SM, Nandigam RN, Delgado P, Betensky RA, Rosand J, Viswanathan A, et al. Microbleeds versus macrobleeds: evidence for distinct entities. Stroke. (2009) 40:2382-6. doi: 10.1161/STROKEAHA.109. 548974

106. Brouwers HB, Biffi A, Ayres AM, Schwab K, Cortellini L, Romero $\mathrm{JM}$, et al. Apolipoprotein E genotype predicts hematoma expansion in lobar intracerebral hemorrhage. Stroke. (2012) 43:1490-5. doi: 10.1161/STROKEAHA.111.643262

107. Murai Y, Takagi R, Ikeda Y, Yamamoto Y, Teramoto A. Threedimensional computerized tomography angiography in patients with hyperacute intracerebral hemorrhage. J Neurosurg. (1999) 91:424-31. doi: $10.3171 /$ jns.1999.91.3.0424 
108. Lee KR, Kawai N, Kim S, Sagher O, Hoff JT. Mechanisms of edema formation after intracerebral hemorrhage: effects of thrombin on cerebral blood flow, blood-brain barrier permeability, and cell survival in a rat model. J Neurosurg. (1997) 86:272-8. doi: 10.3171/jns.1997.86.2.0272

109. Rosenberg GA, Navratil M. Metalloproteinase inhibition blocks edema in intracerebral hemorrhage in the rat. Neurology. (1997) 48:921-6. doi: 10.1212/WNL.48.4.921

110. Xi G, Wagner KR, Keep RF, Hua Y, de Courten-Myers GM, Broderick JP, et al. Role of blood clot formation on early edema development after experimental intracerebral hemorrhage. Stroke. (1998) 29:2580-6. doi: 10.1161/01.STR.29.12.2580

111. Zhang Z, Zhang Z, Lu H, Yang Q, Wu H, Wang J. Microglial polarization and inflammatory mediators after intracerebral hemorrhage. Mol Neurobiol. (2017) 54:1874-86. doi: 10.1007/s12035-016-9785-6

112. Anderson CS, Huang Y, Wang JG, Arima H, Neal B, Peng B, et al. Intensive blood pressure reduction in acute cerebral haemorrhage trial (INTERACT): a randomised pilot trial. Lancet Neurol. (2008) 7:391-9. doi: 10.1016/S1474-4422(08)70069-3

113. Qureshi AI, Majidi S, Gilani WI, Palesch YY, Martin R, Novitzke $\mathrm{J}$, et al. Increased brain volume among good grade patients with intracerebral hemorrhage. results from the antihypertensive treatment of acute cerebral hemorrhage (ATACH) study. Neurocrit Care. (2014) 20:470-5. doi: 10.1007/s12028-013-9842-1

114. Carcel C, Wang X, Sato S, Stapf C, Sandset EC, Delcourt C, et al. Degree and timing of intensive blood pressure lowering on hematoma growth in intracerebral hemorrhage: intensive blood pressure reduction in acute cerebral hemorrhage trial-2 results. Stroke. (2016) 47:1651-3. doi: 10.1161/STROKEAHA.116.013326

115. Qureshi AI, Palesch YY, Barsan WG, Hanley DF, Hsu CY, Martin $\mathrm{RL}$, et al. Intensive blood-pressure lowering in patients with acute cerebral hemorrhage. $N$ Engl J Med. (2016) 375:1033-43. doi: 10.1056/NEJMoa1603460

116. Morotti A, Boulouis G, Romero JM, Brouwers HB, Jessel MJ, Vashkevich $\mathrm{A}$, et al. Blood pressure reduction and noncontrast CT markers of intracerebral hemorrhage expansion. Neurology. (2017) 89:548-54. doi: 10.1212/WNL.0000000000004210

117. Morotti A, Brouwers HB, Romero JM, Jessel MJ, Vashkevich A, Schwab $\mathrm{K}$, et al. Intensive blood pressure reduction and spot sign in intracerebral hemorrhage: a secondary analysis of a randomized clinical trial. JAMA Neurol. (2017) 74:950-60. doi: 10.1001/jamaneurol.2017.1014

118. Zheng D, Sato S, Arima H, Heeley E, Delcourt C, Cao Y, et al. Estimated GFR and the effect of intensive blood pressure lowering after acute intracerebral hemorrhage. Am J Kidney Dis. (2016) 68:94-102. doi: 10.1053/j.ajkd.2016.01.020

119. Toyoda K, Koga M, Yamamoto H, Foster L, Palesch YY, Wang Y, et al. Clinical outcomes depending on acute blood pressure after cerebral hemorrhage. Ann Neurol. (2019) 85:105-13. doi: 10.1002/ana.25379

120. Gioia LC, Kate M, Choi V, Sivakumar L, Jeerakathil T, Kosior J, et al. Ischemia in intracerebral hemorrhage is associated with leukoaraiosis and hematoma volume, not blood pressure reduction. Stroke. (2015) 46:1541-7. doi: 10.1161/STROKEAHA.114.008304

121. Wu B, Yao X, Lei C, Liu M, Selim MH. Enlarged perivascular spaces and small diffusion-weighted lesions in intracerebral hemorrhage. Neurology. (2015) 85:2045-52. doi: 10.1212/WNL.0000000000002169

122. Garg RK, Liebling SM, Maas MB, Nemeth AJ, Russell EJ, Naidech AM. Blood pressure reduction, decreased diffusion on MRI, and outcomes after intracerebral hemorrhage. Stroke. (2012) 43:67-71. doi: 10.1161/STROKEAHA.111.629493

123. Kidwell CS, Rosand J, Norato G, Dixon S, Worrall BB, James ML, et al. Ischemic lesions, blood pressure dysregulation, and poor outcomes in intracerebral hemorrhage. Neurology. (2017) 88:782-8. doi: 10.1212/WNL.0000000000003630

124. Arima H, Heeley E, Delcourt C, Hirakawa Y, Wang X, Woodward $\mathrm{M}$, et al. Optimal achieved blood pressure in acute intracerebral hemorrhage: INTERACT2. Neurology. (2015) 84:464-71. doi: 10.1212/WNL.0000000000001205

125. Wang X, Arima H, Al-Shahi Salman R, Woodward M, Heeley E, Stapf C, et al. Rapid blood pressure lowering according to recovery at different time intervals after acute intracerebral hemorrhage: pooled analysis of the INTERACT studies. Cerebrovasc Dis. (2015) 39:242-8. doi: $10.1159 / 000381107$

126. Song L, Sandset EC, Arima H, Heeley E, Delcourt C, Chen G, et al. Early blood pressure lowering in patients with intracerebral haemorrhage and prior use of antithrombotic agents: pooled analysis of the INTERACT studies. J Neurol Neurosurg Psychiatry. (2016) 87:1330-5. doi: 10.1136/jnnp-2016-313246

127. Mengel A, Stefanou MI, Hadaschik KA, Wolf M, Stadler V, Poli K, et al. Early administration of desmopressin and platelet transfusion for reducing hematoma expansion in patients with acute antiplatelet therapy associated intracerebral hemorrhage. Crit Care Med. (2020) 48:1009-17. doi: 10.1097/CCM.0000000000004348

128. Ducruet AF, Hickman ZL, Zacharia BE, Grobelny BT, DeRosa PA, Landes $\mathrm{E}$, et al. Impact of platelet transfusion on hematoma expansion in patients receiving antiplatelet agents before intracerebral hemorrhage. Neurol Res. (2010) 32:706-10. doi: 10.1179/174313209X459129

129. Martin M, Conlon LW. Does platelet transfusion improve outcomes in patients with spontaneous or traumatic intracerebral hemorrhage? Ann Emerg Med. (2013) 61:58-61. doi: 10.1016/j.annemergmed.2012.03.025

130. Baharoglu MI, Cordonnier C, Salman RA-S, de Gans K, Koopman MM, Brand A, et al. Platelet transfusion versus standard care after acute stroke due to spontaneous cerebral haemorrhage associated with antiplatelet therapy (PATCH): a randomised, open-label, phase 3 trial. Lancet. (2016) 387:260513. doi: 10.1016/S0140-6736(16)30392-0

131. Prodan CI. Platelets after intracerebral haemorrhage: more is not better. Lancet. (2016) 387:2577-8. doi: 10.1016/S0140-6736(16)30478-0

132. Arnone GD, Kumar P, Wonais MC, Esfahani DR, Campbell-Lee SA, Charbel FT, et al. Impact of platelet transfusion on intracerebral hemorrhage in patients on antiplatelet therapy-an analysis based on intracerebral hemorrhage score. World Neurosurg. (2018) 111:e895-904. doi: 10.1016/j.wneu.2018.01.006

133. Naidech AM, Jovanovic B, Liebling S, Garg RK, Bassin SL, Bendok BR, et al. Reduced platelet activity is associated with early clot growth and worse 3month outcome after intracerebral hemorrhage. Stroke. (2009) 40:2398-401. doi: 10.1161/STROKEAHA.109.550939

134. Prodan CI, Stoner JA, Dale GL. Lower coated-platelet levels are associated with increased mortality after spontaneous intracerebral hemorrhage. Stroke. (2015) 46:1819-25. doi: 10.1161/STROKEAHA.115.009068

135. Naidech AM, Bassin SL, Bernstein RA, Batjer HH, Alberts MJ, Lindholm PF, et al. Reduced platelet activity is more common than reported anti-platelet medication use in patients with intracerebral hemorrhage. Neurocrit Care. (2009) 11:307-10. doi: 10.1007/s12028-009-9219-7

136. Naidech AM, Maas MB, Levasseur-Franklin KE, Liotta EM, Guth JC, Berman $\mathrm{M}$, et al. Desmopressin improves platelet activity in acute intracerebral hemorrhage. Stroke. (2014) 45:2451-3. doi: 10.1161/STROKEAHA.114.006061

137. Switzer JA, Rocker J, Mohorn P, Waller JL, Hughes D, Bruno A, et al. Clinical experience with three-factor prothrombin complex concentrate to reverse warfarin anticoagulation in intracranial hemorrhage. Stroke. (2012) 43:2500-2. doi: 10.1161/STROKEAHA.112.661454

138. Frontera JA, Lewin JJ. III, Rabinstein AA, Aisiku IP, Alexandrov AW, Cook AM, et al. Guideline for reversal of antithrombotics in intracranial hemorrhage: a statement for healthcare professionals from the neurocritical care society and society of critical care medicine. Neurocrit Care. (2016) 24:6-46. doi: 10.1007/s12028-015-0222-x

139. Sarode R, Milling TJ Jr, Refaai MA, Mangione A, Schneider A, Durn BL, et al. Efficacy and safety of a 4-factor prothrombin complex concentrate in patients on vitamin $\mathrm{K}$ antagonists presenting with major bleeding: a randomized, plasma-controlled, phase IIIb study. Circulation. (2013) 128:1234-43. doi: 10.1161/CIRCULATIONAHA.113.002283

140. Frontera JA, Gordon E, Zach V, Jovine M, Uchino K, Hussain MS, et al. Reversal of coagulopathy using prothrombin complex concentrates is associated with improved outcome compared to fresh frozen plasma in warfarin-associated intracranial hemorrhage. Neurocrit Care. (2014) 21:397406. doi: 10.1007/s12028-014-9972-0

141. Majeed A, Meijer K, Larrazabal R, Arnberg F, Luijckx GJ, Roberts RS, et al. Mortality in vitamin $\mathrm{K}$ antagonist-related intracerebral bleeding treated with 
plasma or 4-factor prothrombin complex concentrate. Thromb Haemost. (2014) 111:233-9. doi: 10.1160/TH13-07-0536

142. Goldstein JN, Refaai MA, Milling TJ, Lewis B, Goldberg-Alberts R, Hug BA, et al. Four-factor prothrombin complex concentrate versus plasma for rapid vitamin $\mathrm{K}$ antagonist reversal in patients needing urgent surgical or invasive interventions: a phase $3 \mathrm{~b}$, open-label, non-inferiority, randomised trial. Lancet. (2015) 385:2077-87. doi: 10.1016/S0140-6736(14)61685-8

143. Huhtakangas J, Tetri S, Juvela S, Saloheimo P, Bode MK, Karttunen V, et al. Improved survival of patients with warfarin-associated intracerebral haemorrhage: a retrospective longitudinal population-based study. Int $J$ Stroke. (2015) 10:876-81. doi: 10.1111/j.1747-4949.2012.00926.x

144. Steiner T, Poli S, Griebe M, Hüsing J, Hajda J, Freiberger A, et al. Fresh frozen plasma versus prothrombin complex concentrate in patients with intracranial haemorrhage related to vitamin $\mathrm{K}$ antagonists (INCH): a randomised trial. Lancet Neurol. (2016) 15:566-73. doi: 10.1016/S1474-4422(16)00110-1

145. Lu G, DeGuzman FR, Hollenbach SJ, Karbarz MJ, Abe K, Lee G, et al. A specific antidote for reversal of anticoagulation by direct and indirect inhibitors of coagulation factor Xa. Nat Med. (2013) 19:446-51. doi: $10.1038 / \mathrm{nm} .3102$

146. Ansell JE, Bakhru SH, Laulicht BE, Steiner SS, Grosso M, Brown K, et al. Use of PER977 to reverse the anticoagulant effect of edoxaban. N Engl J Med. (2014) 371:2141-2. doi: 10.1056/NEJMc1411800

147. Glund S, Stangier J, Schmohl M, Gansser D, Norris S, van Ryn J, et al. Safety, tolerability, and efficacy of idarucizumab for the reversal of the anticoagulant effect of dabigatran in healthy male volunteers: a randomised, placebo-controlled, double-blind phase 1 trial. Lancet. (2015) 386:680-90. doi: 10.1016/S0140-6736(15)60732-2

148. Pollack CVJr, Reilly PA, Eikelboom J, Glund S, Verhamme P, Bernstein RA, et al. Idarucizumab for dabigatran reversal. N Engl J Med. (2015) 373:511-20. doi: 10.1056/NEJMoa1502000

149. Siegal DM, Curnutte JT, Connolly SJ, Lu G, Conley PB, Wiens BL, et al. Andexanet alfa for the reversal of factor Xa inhibitor activity. $N$ Engl J Med. (2015) 373:2413-24. doi: 10.1056/NEJMoa1510991

150. Connolly SJ, Milling TJ Jr, Eikelboom JW, Gibson CM, Curnutte JT, Gold A, et al. Andexanet alfa for acute major bleeding associated with factor Xa inhibitors. N Engl J Med. (2016) 375:1131-41. doi: 10.1056/NEJMoa 1607887

151. Pollack CV Jr, Reilly PA, van Ryn J, Eikelboom JW, Glund S, Bernstein RA, et al. Idarucizumab for dabigatran reversal - full cohort analysis. $\mathrm{N} \mathrm{Engl} \mathrm{J}$ Med. (2017) 377:431-41. doi: 10.1056/NEJMoa1707278

152. Mayer SA, Brun NC, Begtrup K, Broderick J, Davis S, Diringer MN, et al. Recombinant activated factor VII for acute intracerebral hemorrhage. $N$ Engl J Med. (2005) 352:777-85. doi: 10.1056/NEJMoa042991

153. Mayer SA, Brun NC, Begtrup K, Broderick J, Davis S, Diringer MN, et al. Efficacy and safety of recombinant activated factor VII for acute intracerebral hemorrhage. N Engl J Med. (2008) 358:2127-37. doi: 10.1056/NEJMoa0707534

154. Yuan ZH, Jiang JK, Huang WD, Pan J, Zhu JY, Wang JZ. A meta-analysis of the efficacy and safety of recombinant activated factor VII for patients with acute intracerebral hemorrhage without hemophilia. J Clin Neurosci. (2010) 17:685-93. doi: 10.1016/j.jocn.2009.11.020

155. Gladstone DJ, Aviv RI, Demchuk AM, Hill MD, Thorpe KE, Khoury JC, et al. Effect of recombinant activated coagulation factor VII on hemorrhage expansion among patients with spot sign-positive acute intracerebral hemorrhage: the SPOTLIGHT and STOP-IT randomized clinical trials. JAMA Neurol. (2019) 76:1493-501. doi: 10.1001/jamaneurol.2019.2636

156. Diringer MN, Skolnick BE, Mayer SA, Steiner T, Davis SM, Brun $\mathrm{NC}$, et al. Risk of thromboembolic events in controlled trials of rFVIIa in spontaneous intracerebral hemorrhage. Stroke. (2008) 39:850-6. doi: 10.1161/STROKEAHA.107.493601

157. Schmidt ML, Gamerman S, Smith HE, Scott JP, DiMichele DM. Recombinant activated factor VII (rFVIIa) therapy for intracranial hemorrhage in hemophilia A patients with inhibitors. Am J Hematol. (1994) 47:36-40. doi: 10.1002/ajh.2830470108

158. Mayer SA, Davis SM, Skolnick BE, Brun NC, Begtrup K, Broderick JP, et al. Can a subset of intracerebral hemorrhage patients benefit from hemostatic therapy with recombinant activated factor VII? Stroke. (2009) 40:833-40. doi: 10.1161/STROKEAHA.108.524470

159. Sprigg N, Flaherty K, Appleton JP, Al-Shahi Salman R, Bereczki D, Beridze $\mathrm{M}$, et al. Tranexamic acid to improve functional status in adults with spontaneous intracerebral haemorrhage: the TICH-2 RCT. Health Technol Assess. (2019) 23:1-48. doi: 10.3310/hta23350

160. Hu W, Xin Y, Chen X, Song Z, He Z, Zhao Y. Tranexamic acid in cerebral hemorrhage: a meta-analysis and systematic review. CNS Drugs. (2019) 33:327-336. doi: 10.1007/s40263-019-00608-4

161. Ovesen C, Jakobsen JC, Gluud C, Steiner T, Law Z, Flaherty K, et al. Prevention of haematoma progression by tranexamic acid in intracerebral haemorrhage patients with and without spot sign on admission scan: a statistical analysis plan of a pre-specified sub-study of the TICH-2 trial. BMC Res Notes. (2018) 11:379. doi: 10.1186/s13104-018-3481-8

162. Gray CS, Hildreth AJ, Sandercock PA, O'Connell JE, Johnston DE, Cartlidge $\mathrm{NE}$, et al. Glucose-potassium-insulin infusions in the management of poststroke hyperglycaemia: the UK glucose insulin in stroke trial (GIST-UK). Lancet Neurol. (2007) 6:397-406. doi: 10.1016/S1474-4422(07)70080-7

163. Finfer S, Chittock DR, Su SY, Blair D, Foster D, Dhingra V, et al. Intensive versus conventional glucose control in critically ill patients. $N$ Engl J Med. (2009) 360:1283-97. doi: 10.1056/NEJMoa0810625

164. Godoy DA, Di Napoli M, Rabinstein AA. Treating hyperglycemia in neurocritical patients: benefits and perils. Neurocrit Care. (2010) 13:425-38. doi: 10.1007/s12028-010-9404-8

165. Zheng Y, Hu Q, Manaenko A, Zhang Y, Peng Y, Xu L, et al. 17betaestradiol attenuates hematoma expansion through estrogen receptor alpha/silent information regulator 1/nuclear factor-kappa b pathway in hyperglycemic intracerebral hemorrhage mice. Stroke. (2015) 46:485-91. doi: 10.1161/STROKEAHA.114.006372

166. Alvarez-Sabin J, Delgado P, Abilleira S, Molina CA, Arenillas J, Ribo $\mathrm{M}$, et al. Temporal profile of matrix metalloproteinases and their inhibitors after spontaneous intracerebral hemorrhage: relationship to clinical and radiological outcome. Stroke. (2004) 35:1316-22. doi: $10.1161 / 01 . S T R .0000126827 .69286 .90$

167. Chang JJ, Emanuel BA, Mack WJ, Tsivgoulis G, Alexandrov AV. Matrix metalloproteinase-9: dual role and temporal profile in intracerebral hemorrhage. J Stroke Cerebrovasc Dis. (2014) 23:2498-505. doi: 10.1016/j.jstrokecerebrovasdis.2014.07.005

168. Rodriguez JA, Sobrino T, Lopez-Arias E, Ugarte A, Sanchez-Arias JA, VieitesPrado A, et al. CM352 reduces brain damage and improves functional recovery in a rat model of intracerebral hemorrhage. J Am Heart Assoc. (2017) 6:e006042. doi: 10.1161/JAHA.117.006042

169. Peeling J, Del Bigio MR, Corbett D, Green AR, Jackson DM. Efficacy of disodium 4-[(tert-butylimino)methyl]benzene-1,3-disulfonate $\mathrm{N}$ oxide (NXY-059), a free radical trapping agent, in a rat model of hemorrhagic stroke. Neuropharmacology. (2001) 40:433-9. doi: 10.1016/S0028-3908(00)00170-2

170. Lyden PD, Shuaib A, Lees KR, Davalos A, Davis SM, Diener HC, et al. Safety and tolerability of NXY-059 for acute intracerebral hemorrhage: the CHANT trial. Stroke. (2007) 38:2262-9. doi: 10.1161/STROKEAHA.106. 472746

171. Imai T, Iwata S, Miyo D, Nakamura S, Shimazawa M, Hara H. A novel free radical scavenger, NSP-116, ameliorated the brain injury in both ischemic and hemorrhagic stroke models. J Pharmacol Sci. (2019) 141:11926. doi: $10.1016 /$ j.jphs.2019.09.012

172. Lee ST, Chu K, Sinn DI, Jung KH, Kim EH, Kim SJ, et al. Erythropoietin reduces perihematomal inflammation and cell death with eNOS and STAT3 activations in experimental intracerebral hemorrhage. J Neurochem. (2006) 96:1728-39. doi: 10.1111/j.1471-4159.2006.03697.x

173. Sinn DI, Kim SJ, Chu K, Jung KH, Lee ST, Song EC, et al. Valproic acid-mediated neuroprotection in intracerebral hemorrhage via histone deacetylase inhibition and transcriptional activation. Neurobiol Dis. (2007) 26:464-72. doi: 10.1016/j.nbd.2007.02.006

174. Lee ST, Chu K, Jung KH, Kim J, Kim EH, Kim SJ, et al. Memantine reduces hematoma expansion in experimental intracerebral hemorrhage, resulting in functional improvement. J Cereb Blood Flow Metab. (2006) 26:536-44. doi: $10.1038 /$ sj.jcbfm. 9600213 
175. King MD, McCracken DJ, Wade FM, Meiler SE, Alleyne CHJr, Dhandapani KM. Attenuation of hematoma size and neurological injury with curcumin following intracerebral hemorrhage in mice. J Neurosurg. (2011) 115:116-23. doi: 10.3171/2011.2.JNS10784

176. Belayev L, Saul I, Busto R, Danielyan K, Vigdorchik A, Khoutorova L, et al. Albumin treatment reduces neurological deficit and protects blood-brain barrier integrity after acute intracortical hematoma in the rat. Stroke. (2005) 36:326-31. doi: 10.1161/01.STR.0000152949.31366.3d

177. Wang J, Tsirka SE. Tuftsin fragment $1-3$ is beneficial when delivered after the induction of intracerebral hemorrhage. Stroke. (2005) 36:613-8. doi: 10.1161/01.STR.0000155729.12931.8f
Conflict of Interest: The authors declare that the research was conducted in the absence of any commercial or financial relationships that could be construed as a potential conflict of interest.

Copyright (c) $2020 \mathrm{Li}$, You, Long, Bi, Xu, He and Hu. This is an open-access article distributed under the terms of the Creative Commons Attribution License (CC BY). The use, distribution or reproduction in other forums is permitted, provided the original author(s) and the copyright owner(s) are credited and that the original publication in this journal is cited, in accordance with accepted academic practice. No use, distribution or reproduction is permitted which does not comply with these terms. 